\title{
Dificuldades de aprendizagem dos alunos do ensino fundamental: intervenções do professor
}

\author{
Learning difficulties in \\ elementary students: \\ teachers' interventions
}

\author{
Sônia Aparecida Belletti CRUZ* \\ Maria Cristina Bergonzoni STEFANINI**
}

\begin{abstract}
Resumo: A preocupação e o desconforto com o comportamento e o baixo desempenho de crianças com dificuldade de aprendizagem e a atuação de seus professores no cotidiano de sala de aula nos instigaram a realizar o presente estudo. Baseados nos princípios teóricos de Piaget e Vygotsky, buscamos conhecer, por meio de entrevista semiestruturada, o que dizem os professores sobre a sua atuação para ajudar os alunos no enfrentamento das dificuldades de aprendizagem e como é a resposta do aluno após a ação do professor. Os sujeitos são oito professores de $1^{\mathrm{a}}$ a $4^{\mathrm{a}}$ séries de uma escola pública estadual da cidade de Araraquara-SP. Os resultados mostram que a intervenção dos professores pode ser classificada em estratégias pedagógicas e estratégias afetivas. Pedagogicamente, dizem utilizar atividades diferenciadas e encaminhar o aluno ao reforço escolar. Afetivamente, motivam e incentivam as crianças, através de conversas, elogios e advertências. Os alunos percebem a ação do professor e reagem de forma positiva, demonstrando entusiasmo na realização das atividades e carinho, presenteando o professor com seus "feitos" e aproximando-se fisicamente dele. Acreditamos que a concepção e a intervenção do professor sobre difículdades de aprendizagem são resultado de como ele aprendeu a ensinar e de sua vivência no ambiente escolar no qual está inserido. Dessa forma, expressam a compreensão atual de sua estratégia docente.
\end{abstract}

Palavras-chave: aprendizagem, dificuldades de aprendizagem, fracasso escolar

\footnotetext{
* Mestre em Educação Escolar pela UNESP-Araraquara. Vice-diretora de escola pública estadual de Ensino Fundamental-SP. Email: soniabelletti@yahoo.com.br

${ }^{* *}$ Professora-Assistente-Doutora, Departamento de Psicologia da Educação, FCL-UnespAraraquara-SP. Email: cristina@fclar.unesp.br
}

Olhar de professor, Ponta Grossa, 8(1): 151-170, 2005. 


\begin{abstract}
Concern with the behaviour and unsatisfactory academic performance of children with learning difficulties and the role of their teachers in a classroom environment, motivated us to develop the present study. Based on Piaget and Vigotsky's principles and using a semi-structured interview, we sought to find out what teachers say about their performance in helping students to face their own learning difficulties as well as examining students' responses to teachers' actions. The subjects of the present study are eight elementary school teachers from the first to the fourth grades, working at a state school in the town of Araraquara-SP. The results show that teachers' actions can be classified into pedagogical and affective strategies. Pedagogically speaking, the teachers say that they use different activities and suggest additional classroom support. Affectively, they motivate and encourage the children by talking to them, praising or giving them advice. The students notice the teachers' manner and react positively demonstrating enthusiasm during the activities, and handing in their achievements while approaching the teachers physically. We believe that the teacher's conception regarding learning difficulties is the result of how he/she learned to teach and are based on his/her school experience. Both these aspects show understanding of his/her ability dealing with strategies.
\end{abstract}

Key words: learning, learning difficulties, school failure

Uma questão que sempre nos causou preocupação é a dificuldade na aprendizagem que certos alunos apresentam em sala de aula. Algumas situações, como os casos de alunos que não querem realizar suas atividades e de outros que, por motivos corriqueiros, xingam e batem nos colegas, sempre nos causaram estranheza e descontentamento, também.

Diante disso, as seguintes questões podem ser formuladas: como os professores compreendem o processo de aprendizagem da criança e as suas dificuldades para aprender? Os professores conhecem a melhor forma de intervir no processo de aprendizagem de seus alunos?

Com este trabalho, visamos a con- tribuir para o debate de tais questões, apresentando informações que possam habilitar a equipe escolar e, especialmente, os professores na compreensão dos problemas que seus alunos apresentam na escola e das várias formas de intervenção capazes de efetivar a aprendizagem das crianças.

\section{DESENVOLVIMENTO INTELEC- TUALEAPRENDIZAGEMNATEO- RIA PIAGETIANA ENA PERSPEC- TIVASÓCIO-HISTÓRICA}

A teoria piagetiana considera que as formas de pensamento constroemse na interação da criança com os objetos, através da ação. O sujeito conhece o objeto assimilando-o a 
seus esquemas. No decorrer de seu desenvolvimento, a criança passa a reorganizar e reconstruir esses esquemas, diversificando-os, diferenciando-os e combinando-os.

Piaget (1998) introduz três conceitos fundamentais no estudo do desenvolvimento intelectual e que estão estreitamente relacionados: assimilação, acomodação e equilibração.

A assimilação é definida como um mecanismo de incorporação das particularidades, qualidades dos objetos aos esquemas ou estruturas intelectuais que o sujeito dispõe em certo momento. A acomodação refere-se ao mecanismo complementar em que os esquemas ou estruturas do sujeito devem se ajustar às propriedades $\mathrm{e}$ particularidades do objeto. A equilibração é o processo geral em que o indivíduo deve compensar ativamente as perturbações que o meio oferece, ou seja, obstáculos, dificuldades encontradas, resistências do objeto a ser assimilado.

Piaget (1998, (p. 13) afirma que o desenvolvimento intelectual da criança provém de "uma equilibração progressiva, uma passagem contínua de um estado de menos equilíbrio para um estado de equilíbrio superior". Cada estágio de desenvolvimento constitui, portanto, uma forma particular de equilíbrio e a seqüência da evolução mental caracteriza uma equilibração sempre completa.

De acordo com Piaget e Grécco (1974), há uma distinção entre aprendizagem no sentido estrito e aprendi- zagem no sentido amplo. No sentido estrito, a aprendizagem compreende o conhecimento adquirido através da experiência, podendo ser do tipo físico ou lógico-matemático, ou mesmo os dois. No sentido amplo, a aprendizagem é um processo adaptativo que vai se desenvolvendo no tempo e que se confunde com o próprio desenvolvimento. Ocorre pela ação da experiência do sujeito e do processo de equilibração.

Uma outra abordagem a respeito da aprendizagem é liderada pelos estudos de Vygotsky (1991), chamada de sócio-histórica ou sócio-cultural. Nessa abordagem, aprendizagem é o resultado da interação dinâmica da criança com o meio social na constituição de sua capacidade cognitiva e é produto do entrelaçamento do pensamento e da linguagem, que se constitui no nível mais alto de funcionamento cognitivo, pois envolve a reflexão, o planejamento e a organização, propiciados pelo pensamento verbal, que é construído pela mediação simbólica ou social. Desenvolve os conceitos de zona de desenvolvimento proximal e aprendizagem mediada.

A respeito do conceito de zona de desenvolvimento proximal, são considerados dois níveis de desenvolvimento: o real, que exprime o desempenho da criança ao realizar suas tarefas de forma autônoma; e o potencial, aquele alcançado quando a criança recebe ajuda do outro.

Dentro da abordagem vygotskyana, Linhares (1998) dedicou-se 
em seus estudos aos conceitos de aprendizagem mediada, na qual a aprendizagem depende de uma pessoa mais capaz para promover o desenvolvimento do indivíduo.

\section{CONCEPÇÕES DE DIFICULDADE DEAPRENDIZAGEM}

Segundo Campos (1997), os termos mais utilizados na escola são dificuldade ou problema de aprendizagem. A dificuldade de aprendizagem refere-se a alguma desordem na aprendizagem geral da criança e provém de fatores reversíveis. Normalmente, não há causas orgânicas.

A definição sugerida por García (1998) é a proposta pelo National Joint Committee on Learning Disabilities:

Dificuldade de Aprendizagem (D.A.) é um termo geral que se refere a um grupo heterogêneo de transtornos que se manifestam por dificuldades significativas na aquisição e uso da escuta, fala, leitura, escrita, raciocínio ou habilidades matemáticas. Esses transtornos são intrínsecos ao indivíduo, supondo-se devido à disfunção do sistema nervoso central, e podem ocorrer ao longo do ciclo vital. Podem existir, junto com as dificuldades de aprendizagem, problemas nas condutas de auto-regulação, percepção social e interação social, mas não constituem, por si pró- prias, uma dificuldade de aprendizagem. Ainda que as dificuldades de aprendizagem possam ocorrer concomitantemente com outras condições incapacitantes (por exemplo, deficiência sensorial, retardamento mental, transtornos emocionais graves) ou com influências extrínsecas (tais como as diferenças culturais, instrução inapropriada ou insuficiente), não são resultados dessas condições ou influências. (GARCÍA, 1998, p. 31-32).

Pelegrini e Golfeto (1998) afirmam que, dentro da estrutura escolar, as crianças - de acordo com a sua idade e o seu nível de desenvolvimento intelectual - têm várias realizações a apresentar e que nem todas conseguem obter sucesso nessa empreitada, não demonstrando assim desempenho satisfatório.

Segundo Jacob e Loureiro (1996), a dificuldade escolar tem repercussão nos processos intra-psíquicos ligados à formação da identidade, provocando dificuldades afetivas, também.

Weiss (1997, p. 16) considera o fracasso escolar como "uma resposta insuficiente do aluno a uma exigência ou demanda da escola". Essa insuficiência escolar pode estar ligada à ausência de estrutura cognoscitiva, que permite a organização dos estímulos e favorece a aquisição dos conhecimentos. Todavia, a dificuldade em aprender pode estar relacionada a determinantes sociais, da escola e do 
próprio aluno, ou seja, ligada a fatores internos (cognitivos e emocionais) e a fatores externos (culturais, sociais e políticos) (JACOB; LOUREIRO, 1996; WEISS, 1997). Segundo Chakur e Ravagnani (2001), geralmente o fracasso é do sistema escolar e educacional, bem como do contexto escolar.

Schliemann, Carraher e Carraher (1995) também atribuem o fracasso escolar da criança à instituição escolar. Os conhecimentos informais aplicados pelas crianças em situações cotidianas (mesmo as técnicas que funcionam bem e levam ao resultado certo) não são aproveitados pela escola e são considerados inadequados para a aprendizagem.

Jacob e Loureiro (1996) salientam que o fato da criança apresentar dificuldade de aprendizagem não pode ser considerado um problema isolado, de pouca preocupação, já que o fracasso escolar interfere no desenvolvimento afetivo e compromete processos intra-psiquícos relacionados à formação da personalidade da criança, o que acarreta problemas afetivos, também. Disso advém a necessidade de proporcionar cuidados especiais a essa criança.

Del Prette e Del Prette (1998), no enfoque das habilidades sociais, dentro do aspecto interpessoal, entendem as dificuldades de aprendizagem como uma "síndrome psicossocial" que sofre interferência de fatores tanto de ordem interna quanto externa, no que diz respeito ao meio familiar, pedagógico e social.
Estudos apontam que a problemática na área afetivo-social e desempenho acadêmico se correlacionam, ou seja, que crianças com dificuldade de aprendizagem também apresentam problemas socioemocionais e comportamentais (JACOB; LOUREIRO, 1996; MACHADO; MARTURANO; LOUREIRO; LINHARES; BESSA, 1994).

Em termos comportamentais, esses estudos observam crianças imaturas, ansiosas, sem auto-confiança, inseguras, introvertidas e depressivas. Contudo, algumas podem manifestar-se contrariamente: extrovertidas, agressivas, hiperativas e até delinqüentes.

Portanto, os estudos mostram que crianças com dificuldade de aprendizagem parecem demonstrar pouca capacidade adaptativa tanto em casa, como na escola, isto é, a criança apresenta dificuldade em adaptar-se aos dados da realidade que a cerca, comprometendo as possibilidades de seu desenvolvimento cognitivo e emocional.

\section{A FORMAÇÃODE PROFESSORES ESUAESTREITARELAÇÃOCOM AAPRENDIZAGEMDOS ALUNOS}

Pérez Gomes (1992) salienta que a formação de professores adotada em muitas instituições, entendida apenas como um processo de socialização e indução profissional na prática de sala de aula, sem recorrer ao apoio conceptual e teórico da investigação, conduz à reprodução de vícios, pre- 
conceitos e mitos acumulados no decorrer da prática docente.

Para Marcelo (1998), quando o professor intervém na aprendizagem do aluno, além de processar o conhecimentona-ação (aquele conhecimento dinâmico e espontâneo sobre como fazer as coisas), ele processa a reflexão-na-ação, que é o seu pensar sobre o que está fazendo enquanto faz. É a sua atuação consciente que inclui improvisação, combinação e recombi-nação de elementos de uma certa situação.

Segundo Cavaco (1991), o professor deve ser visto como uma pessoa na sua relação com o mundo, com a sua própria história e consigo mesmo, com seus mitos e fantasmas. A sua origem social e os grupos aos quais pertence geram um envolvimento que se reflete na sua vida. Cada um faz seu percurso profissional e, nesse percurso, a etapa em que se situa, também influencia na forma como ele atua na sala de aula com seus alunos.

Villa Sanches (1988), ao tratar da docência nas escolas, coloca que a explosão escolar, o aumento da escolarização e a gratuidade do ensino são alguns fatores que incidem sobre a necessidade de mudança da função docente, no que se refere ao comportamento e atitude do professor para com o aluno no contexto educativo, já que ele é o responsável pela mediação entre esse contexto, o aluno e o desenvolvimento de sua aprendizagem. Ao professor é exigido o domínio de aspectos sociais e emotivos, para promover a integração cultural, assim como de valores sociais para a vivência e experiência de vida dos alunos.

Candau (1996) também mostra preocupação com a formação do professor quando se refere à formação continuada e critica os cursos de modelo clássico, por darem ênfase à reciclagem dos professores, privilegiando o locus da Universidade. Segundo a autora, novas perspectivas de educação continuada repensam essa formação na própria escola, tendo como referência fundamental o saber docente.

Marin (1996), em reflexões que vem fazendo ao longo de seus estudos, inferiu que há um equívoco nos cursos de formação de professores, um equívoco no paradigma básico que os sustenta, qual seja: os cursos de formação não têm considerado os conhecimentos trazidos pelos professores, consideram apenas o conhecimento dos cursos de formação. $\mathrm{Na}$ verdade, a gênese da formação se dá no cotidiano do professor.

Para a autora é preciso adotar um paradigma com fundamentos histórico e social, para que se busque levantar histórico de vida, processo de socialização, expectativas, crenças, valores, enfim, as representações iniciais dos alunos (futuros professores), que deverão ser articuladas com os conteúdos do próprio curso. Dessa forma, será incorporada neles "uma concepção mais ecológica que permita a articulação das vivências dos alunos com um projeto político-pedagógico de curso em que os desejos que 
temos em relação à formação de professores se concretizem" (p. 163).

Surge-nos, então, a idéia de que, se os professores são assim formados, como tratam seus alunos, no que se refere às dificuldades de aprendizagem que eles muitas vezes apresentam?

Embora de formas diferentes, notamos que a opinião dos autores estudados converge para a necessidade de uma continuidade na formação inicial do professor, numa permanente atualização e aprimoramento dos seus conhecimentos.

A respeito dos conhecimentos docentes, os autores mostram que, antes de o professor iniciar sua formação, ele já "possui" sua a cultura de escola. No seu percurso profissional, à medida que vai amadurecendo pessoal e profissionalmente, o professor vai mudando e ampliando suas idéias.

\section{MÉTODO}

O trabalho em questão é um estudo descritivo, de caráter qualitativo, embasado nos moldes apresentados por Selltiz et al. (1965), Lüdke e André (1986), Triviños (1992) e Minayo (1998). Consta da descrição e interpretação dos resultados obtidos por meio de entrevista semi-estuturada, com questões abertas, realizada com os professores.

A pesquisa foi realizada numa escola pública estadual, de séries iniciais do Ensino Fundamental, situada no centro da cidade de Araraquara SP. Os sujeitos do referido estudo são oito professores de $1^{\mathrm{a}}$ a $4^{\mathrm{a}}$ série do Ensino Fundamental (um de cada série, nos dois períodos - manhã e tarde), de 23 que lecionam na escola.

Para atingirmos respostas satisfatórias às questões levantadas em nossa pesquisa, utilizamos a entrevista semi-estruturada, individualizada, de registro oral, com gravação direta e com transcrição fiel como procedimento de coleta de dados.

\section{RESULTADOS E DISCUSSÃO}

As respostas dos professores foram organizadas em categorias para que fizéssemos a análise qualitativa:

\section{1 - O que os professores dizem fazer para enfrentar a dificuldade de apren- dizagem de seu aluno}

As respostas dos professores mostram que, para ajudar os alunos a sanarem suas dificuldades na aprendizagem, eles utilizam estratégias pedagógicas e estratégias afetivas.

\section{Estratégias Pedagógicas}

Eis as afirmações dos sujeitos:

"Encaminhamos pro especialista, eu passo alguma coisa no caderno. No caso, está sendo atividade diferente." (prof. A-1 $\left.\mathbf{1}^{\mathbf{a}} \mathbf{s .}\right)$

"Quando eu percebo que a criança está com dificuldades eu vou esgotar as minhas possibilidades. Quando eu estou vendo 
que tudo o que eu estou fazendo não está adiantando, a coordenadora fica sabendo tudo o que está se passando, a diretora está sabendo. Então, encaminho pro grupo de reforço. Quando também não está dando resultado, como eu tenho esse ano, eu chamo os pais. Quando eu vejo também que com os pais não está adiantando, eu peço o encaminhamento, pra fazer a avaliação.

Eu acho que o professor faz de tudo! Eu mudo totalmente o esquema de trabalhar, se eles estão com a letra cursiva, eu volto só pra a letra de forma, atividades especiais, leituras especiais. Outros tipos de atividades que podem chamar mais a atenção desse aluno, que vão despertar neste aluno o interesse." (prof. B-1 $\left.{ }^{\mathrm{a}} \mathbf{s .}\right)$

"A gente dá tarefas adequadas para irem desenvolvendo, pra irem crescendo. A gente dá muita atividade diferenciada pra essas crianças.” (prof. C-2 ${ }^{\mathrm{a}}$ s.)

“... a gente tem a ficha dele, individual, do ano passado... Ai, você já vai conhecer mais um pouco a dificuldade dele. E vai tentando, até acertar! E tem o Reforço."

“... desses dois, eu pedi pra que levassem (no especialista). Eu estou ensinando coisas diferentes pra ele. Coisas de $1^{a}$ série." (prof. D-2 ${ }^{\text {a }}$.)
"Porque você experimenta de todas as maneiras ... coloca o material concreto, retoma, vai e volta lá nos conceitos iniciais, manda a criança à lousa. ... Precisam de um atendimento individualizado,de uma explicação individual, uma assistência um pouco maior. Então, a gente tem que insistir um pouco mais pra que eles terminem, fazendo atividades diferenciadas na classe, chamando mais vezes à lousa, dando explicações, mesmo, individuais no caderno, colocando um coleguinha pra auxiliar." (prof. E-3 ${ }^{\text {a }}$ s.)

“... todas as crianças têm a oportunidade de estar lendo. Eu estou resgatando esse vir à frente pra ler, se levantar e ler. Eu sinto que eles querem participar. Eu dito a matéria e na hora de escrever, quando eu estou ditando, o outro está ali atento. E aquele que tem dificuldade também vê se o outro não errou uma palavrinha, as dificuldades ortográficas. Sempre em parceria, em duplas, um ajudando o outro. Eu espero até o final, se eu vejo que não conseguiu, aí, então eu vou, pra ver se ele está precisando de ajuda, se ele está fazendo certinho. Parece que eles gostam de ser cobrados mesmo (risos). ” (prof. F-3 ${ }^{\mathbf{a}} \mathbf{s .}$ ) “... trabalho em dupla, em grupos. 
Os instrumentos de avaliação são vários. Porque na escola nós temos muitos projetos, nós damos muitas oportunidades, vídeo, por exemplo. Eles assistem e depois têm a oportunidade de se manifestar livremente. Eles têm acesso a livros de literatura, direto na sala de aula, levam pra casa.." (prof. G-4 ${ }^{\mathrm{a}}$ s.)

“...Quando trabalhava em grupo, punha eles um em cada grupo, pra ver se faziam. Ai, no final, eu já fui pondo eles também na atividade junto. É quando os colegas ajudavam, eu ajudava. Aqui, tudo é encaminhado. Eles trabalham muito separado com essa criança. Além do Reforço." (prof. H-4 ${ }^{\text {a }}$ s.)

Nessa primeira categoria, pudemos observar que, ao deparar-se com a dificuldade de aprendizagem do aluno, a conduta de alguns professores é encaminhá-lo a outro profissional. Essa postura nos sugere alguns questionamentos: o professor não se considera responsável pela solução do problema de seu aluno, ou sentese incapaz de solucioná-lo? Ou será que o professor não tem a pretensão de resolver sozinho a dificuldade de aprendizagem que o seu aluno apresenta?

Embora a LDBEN (Lei de Diretrizes e Bases da Educação Nacional), no artigo 13 , ressalte o zelo pela aprendizagem do aluno, inclusive daqueles que têm dificuldade de aprendizagem, observamos que a política educacional vigente corrobora para o seu insuficiente resultado, já que no regime de progressão continuada, esse aluno é encaminhado ao projeto de reforço que, por comportar poucas aulas semanais, muitas vezes é atribuído aos professores recém-formados, que geralmente apresentam pouca ou nenhuma experiência no magistério, deixando-nos a impressão de que pouco ou nenhum resultado positivo alcançam com esses alunos.

Um aspecto por nós considerado positivo é a interação que os professores disseram existir entre eles, a coordenadora pedagógica e a diretora da escola na hora da discussão dos problemas dos alunos. A nosso ver, esse interagir é uma proposta que deveria estender-se e alcançar todas as escolas que se dizem preocupadas em oferecer ensino eficiente e eficaz à solução dos problemas apresentados por alguns alunos.

A proposta de interação entre a equipe escolar é importante, pois, segundo Bueno e Garcia (1996), a escola atua como pólo de pressão e fonte de aprendizagem que determinam e favorecem o êxito dos alunos. Portanto, a escola e os professores dependem do bom desempenho deles para sustentar boa reputação. Nesse sentido, o sucesso escolar pode ser entendido como uma construção que ocorre por meio de crenças e concepções que toda a sociedade tem sobre o sucesso escolar, compreendendo, pois, administradores do sistema es- 
colar, professores, alunos e seus pais. Quando interrogados sobre o tipo de atividades que utilizam para ajudar os alunos a sanarem suas dificuldades, os professores respondem que trabalham individualmente com esses alunos, oferecendo-lhes atividades especiais e diferenciadas, sem, contudo, especificá-las na entrevista.

No entanto, ao descreverem suas estratégias pedagógicas, contraditoriamente, alguns professores disseram utilizar as mesmas atividades para os bons alunos e os que têm dificuldade de aprendizagem, justificandose com as mais variadas explicações. Salientam, porém, que as cobranças é que são diferentes, já que exigem menos daqueles que sabem menos.

Outro ponto que nos parece valer a pena salientar é a prática que os professores dizem ter de trabalhar em grupos de alunos na classe. Segundo eles, esse tipo de atividade agrada as crianças, em especial aquelas que apresentam dificuldade na aprendizagem. Consideram que o trabalho desses alunos com colegas mais avançados na aprendizagem é um bom caminho para a melhora do seu desempenho, já que, junto ao seu igual, o aluno sente-se menos intimidado e mais à vontade para manifestar suas dúvidas. Essa estratégia coincide com as idéias de Coll Salvador (1994), ao afirmar que a prática coletiva de execução de atividades permite produções mais elaboradas e mais corretas que as exibidas pelos alunos individualmente.

A despeito dessa observação do autor supracitado, nossa opinião é de que a atividade coletiva é, também, uma oportunidade de o aluno interagir com o outro e aprender a aceitar o diferente, o divergente. No grupo, ele pode vivenciar situações prazerosas ou conflitantes, mas deverá formular resposta adaptativa que, na maior parte das vezes, será de efeito construtivo ao seu desenvolvimento.

\section{Estratégias Afetivas}

Eis as considerações dos sujeitos: “.... você põe na nota um parabéns, um lindo, um jóia. É sempre um incentivo pra criança. É um elogio." (prof. A-1 $\left.{ }^{\text {a }} \mathbf{s .}\right)$

“... depois de bastante bilhete para casa, chamar a atenção, ele deu uma melhorada.

Ele traz o caderno pra eu corrigir, eu ponho nota, sem fazer nenhum comentário a respeito daquilo. É como se ele tivesse feito tudo certo. Eu expliquei para a Psicóloga da UNESP que não vou forçá-lo, acho que vai ser desgastante pra mim e pra ele. Ele já ta percebendo a diferença. Ele já está descobrindo ... Atividade que ele vai fazer é numa hora que os outros estão fazendo uma outra atividade. Quando ele vem pra fazer a correção do ditado na mesa, são vários que vêm também. Eu não pego só aqueles que estão com dificuldade" (prof. B-1 $\left.{ }^{\mathbf{a}} \mathbf{s .}\right)$

"Tenho que ser mais rigorosa com

Olhar de professor, Ponta Grossa, 8(1): 151-170, 2005. 
ele. Eu não deixo o O. livre, não, porque ele não me deixa dar aula. Mas com a L., tenho que ser muito carinhosa, porque ela é carente, afetivamente. Tento tirar dela o máximo. Ela fica aqui, de pé perto de mim, eu dou o livro, ela fica lendo. Mas como ela tem problema de aprendizagem, o crescimento dela está sempre muito lento. (prof. C-2 ${ }^{\mathrm{a}} \mathbf{s}$.)

“... Ele já está conseguindo ler. Pra mim é uma felicidade! Ah, ele fica todo feliz, também.

Você tem que elogiar o que ele pode fazer de bom. Assim, ele vai fazer sempre mais. Se você fica falando tudo o que ele não sabe, ele não consegue fazer! Porque ele vai pôr nele mesmo. Quanta criança eu já ouvifalar, 'Ah, profa. eu não sei fazer isso, eu sou burro! Minha mãe já falou que eu sou burro!' Por menos que eles façam, eles conseguem fazer. É o que eu sempre falo pra eles. Têm alguns que desanimam na hora. "Ah, profa., eu não estou conseguindo." Eu falei assim: "Todo mundo consegue! A primeira vez eu também não sabia ... a profa. está aqui pra ensinar! Vai ensinar uma, duas, 3, 4 até vocês aprenderem! Tem uns, que uma vez, ensinando vai aprender! Tem uns que não! Precisa 2, 3 vezes... Mas, vai aprender! Todo mundo tem a capacidade de aprender." (prof. D-2 ${ }^{\mathrm{a}}$ s.)
"Da minha parte, eu procuro dar bastante atenção e não humilhar a criança, fazer com que ela entenda que é normal alguns terem dificuldade. Só que tem que estudar mais, tem que treinar mais, fazer mais as coisas em casa. Mas, não vejo que eles tenham algum problema quanto a isso, não! Eles aceitam bem. Agora, por dentro ... Tenho um menininho, que ele é mais quieto. Então, eu não sei bem o que ele pensa.Mas os outros, não. Acho que estão bem integrados, sem problemas." (prof. E-3 $\left.{ }^{\mathbf{a}} \mathbf{s .}\right)$

"Eu não deixo eles ficarem dependentes. Eu cobro. Eu falo: ' Você tem que se virar! Você tem que tentar!' Eu sinto que eles sentem essa necessidade de ser igual ao outro, ter o mesmo rendimento do outro. Apesar de eles não terem ido bem na última prova que nós fizemos, eles sabem que eu não avalio o aluno só pela prova. Então, eles estão na expectativa pra saber como é que vai ficar a média deles. Depois, eu faço um boletinzinho, com a nota, o comportamento, a ordem no caderno, participação. Eles se sentem valorizados com isso."

"Eu acho, que de minha parte, eu fico tranqüila, viu? (risos). Por que eu sou mais que professora pra eles. Acho que eu sou profa. mãezona.Que passa a mão na cabeça, que elogia se a menina pôs um brinquinho, se o meni-

Olhar de professor, Ponta Grossa, 8(1): 151-170, $2005 . \overline{161}$ 
no passou um gel no cabelo. Eles buscam em mim muito mais do que uma professora e eu tenho desempenhado vários papéis. Isso ajuda! No $1^{\circ}$ bimestre, eu chamei os pais, mostrei, falei: 'olha, se eu for avaliar só pela provinha, eles ficariam com rendimento insatisfa-tório. Então, eles vão ficar com satisfatório. 'E eu me sinto bem fazendo isso e ao mesmo tempo eu fico com dúvidas. " (prof. F-3 ${ }^{\text {a }}$.)

“... ela ficou contente por eu incentivar a leitura, falei: 'Muito bem, gostei, está lendo!'

Se vê que ela precisa de muita ajuda psicológica mesmo.

E também não forço: 'Vem na lousa! Não adianta você forçar... vai criar, às vezes, uma situação embaraçosa para a criança. Eu falo: 'Não existe criança burra! Todos vocês são capazes, mais ou menos, todas são capazes!' Então, logo no inicio do ano, fui implantando, quando tomava a leitura dessas crianças... porque eles apresentam aquela dificuldades, os outros davam risada... Eu tinha que parar, chamar a atenção da classe: 'Olha gente, tem que respeitar cada coleguinha! Porque cada um aprende do seu jeito. Você tem que ao invés de dar risada, ajudar o colega, falar vem sentar aqui perto de mim, que eu te ajudo. Quando um de- les participa, eu incentivo a classe a bater palmas... Eles ficam contente." (prof. G-4 $\mathbf{4}^{\mathrm{a}}$ s.)

“Eu comprei um caderno de dez matérias pra ele. Comprei figurinhas, comecei colar as figurinhas. Tudo o que eu dava, eu colava no caderno. No final da aula, ele vinha mostrar o caderno dele pra mim. Ele passou a ter capricho. Até as canetas eu trouxe, coloridas, pra ver se ele se interessava ... Você tem que ter a maior paciência, carinho, compreensão. Porque você vê que não vinha de casa, isso. Você tinha que ir lá falar que estava certo, mesmo que tinha alguma coisa errada." (prof. H-4 ${ }^{\mathbf{a}} \mathbf{s}$.)

Em relação às estratégias afetivas, obtivemos respostas unânimes quanto à intenção de incentivar os alunos com atitudes e palavras motivadoras, embora alguns dissessem que, em certos momentos, precisem ser mais rigorosos com determinados alunos.

Os sujeitos disseram fazer questão de demonstrar aos alunos com dificuldade de aprendizagem que estão preocupados com eles e fazem isso de maneira sutil, sem expor a fragilidade deles. Ressaltam não querer que eles sintam-se envergonhados e diminuídos. Garantem não exercer qualquer conduta que sugira preconceito, discriminação ou rejeição em relação a esses alunos.

Nesse aspecto, podemos retomar a discussão a respeito das profecias 
auto-realizadoras, apresentadas por Carvalho (1996). Quando o professor acredita na capacidade de seu aluno e sinaliza isso para ele, provavelmente alcançará sucesso, haja vista que está intervindo emocionalmente, de forma efetiva no processo ensinoaprendizagem. É no simples olhar, no tocar, no falar com esse aluno que o professor o estimula a executar suas atividades e acreditar que é capaz de fazê-las a contento.

Um sujeito afirmou que, quando seu aluno erra, corrige suas atividades com cuidado, sem falar para ele que estava errado para não humilhálo. Observamos nessa fala o desconforto e o receio que muitos professores sentem em lidar com o erro, tratando-o como um mito. Porém, sabemos que, uma nova abordagem, baseada na perspectiva construtivista, considera que o professor não precisa ter medo do erro e nem obsessão em evitálo. O professor apenas o transforma numa situação de aprendizagem, na qual a criança o supera sem traumas.

Dentro da abordagem psicogenética, o erro é tido como uma fase passageira e inevitável no processo de aprendizagem, que poderá ser revista e superada pelo aluno. Para Davis e Esposito (1991), o erro deve ter o sentido de experimentação: a criança levanta hipóteses, aciona estratégias para colocá-las à prova e, após algumas tentativas, encontrar a melhor solução para aquelas que se revelaram "erradas".

Outro aspecto por nós observa- do é a preocupação que o professor tem em avaliar globalmente o desempenho do aluno, baseando-se não só na prova por ele realizada, mas em tudo o que o aluno realizou. Essa consideração abre discussão para um assunto considerado polêmico e que incomoda muitos educadores: a avaliação do rendimento escolar.

Até bem pouco tempo, pensar em avaliação até bem pouco tempo, era pensar no aluno fazendo prova, a professora no seu papel de juiz, observando o que ele não sabia e dandolhe nota, para aprová-lo ou reproválo: era um mal necessário, já que, quando o aluno não tivesse tirado nota, teria que repetir a mesma série duas, três ou mais vezes para saber mais e tirar nota melhor. Aí sim, poderia passar para a série seguinte.

Mas como bem mostra nosso sujeito $F$, a idéia de avaliação modificouse, ou na pior das hipóteses, vem modificando de alguns tempos para cá, pois hoje já se ressalta a idéia de respeito aos níveis de aprendizagem pelos quais passa uma criança na sua alfabetização. Dessa forma, a avaliação deve se dar pela comparação da aprendizagem anterior com a atual, num processo de acompanhamento do progresso do aluno, num constante trabalho de ação-reflexão-ação (CRUZ, 2000).

Mais uma vez, reafirmamos a idéia de que somente o professor com boa formação terá condição de elaborar as melhores respostas à questões que surgem no cotidiano escolar. 


\section{2 - O que os Professores dizem so- bre a Reação do Aluno quando Per- cebe o Interesse do Professor em Ajudá-lo}

Vejamos os relatos dos professores:

"Ele acata, não responde, não fica revoltado. Só que eu já percebi, que a última vez que ela escreveu um texto, a correção foi feita e eu pedi pra que ela refizesse aquela atividade, ela chorou! Eu acho que ela sentiu assim, que ela estava mais fraca..." (prof. C-2 ${ }^{\mathbf{a}} \mathbf{s .}$

“A I. fica emburrada e o P. , também. Agora, ele já está conseguindo fazer. Ele já está conseguindo ler ... Pra mim é uma felicidade! Chamei outro dia a Rosinha e falei: 'Rosinha, vem aqui ver, porque eu não estou acreditando ele ter conseguido começar a ler.' Ah, ele fica todo feliz, também." (prof. D-2 ${ }^{\mathrm{a}} \mathrm{s}$.)

"Não ficam bravos com a chamada de atenção. Eles atendem bem, retomam o que era pra ser feito, sem problema. As meninas são mais carinhosas, aquele beijinho na hora de ir embora."

"Eles querem fazer mais: 'Passa mais um desse aí.' Eles gostam dessas atividades, de vir na lousa. Acho que eles precisam de um atendimento diferenciado, um pouco mais de atenção ... e realmente eles respondem bem a isso." (prof. E-3 ${ }^{\text {a }}$ s.)
“... ela ficou contente por eu incentivar a leitura, falei: "Muito bem, gostei, está lendo! Ah, como eu fiquei contente!" Aí, ela foi na carteira e fez um desenho, ... que ela desenha muito bem, desenhar é com ela mesma. E me presenteou com o desenho..."

"A criança sente o seu olhar sobre ela.... Você transmite muito à ela... O professor é tudo, né? ... elas reagem de uma maneira assim, mostrando entusiasmo pelo que elas fazem. Elas parecem que, a partir do que você faz por elas, elas sentem mais boa vontade em trabalhar, em produzir e se sentem estimuladas, mesmo."

"Eles demonstram mostrando o fruto do trabalho deles: "Olha, profs., o que eu consegui fazer!"

"Muito bem, você conseguiu chegar até aí, você consegue mais! Eu sei que você consegue mais! ... ele fica todo contente porque ele sentiu que tem alguém que acredita nele." (prof. G-4 ${ }^{\mathbf{a}}$ s.)

Nesta categoria, os sujeitos responderam, de forma geral, que os alunos não se incomodam com a chamada de atenção dos professores, o que vem confirmar a idéia de que quando o professor estabelece limites de forma assertiva e afetiva, os alunos os acatam sem sobressaltos e essa resposta traz bons resultados ao seu desempenho acadêmico.

Nesse aspecto, acreditamos que quando o professor que se mostra 
exigente com o aluno, passando visto no seu caderno, cobrando a pintura de um desenho que ele fez, solicitando a devolução de um livro que ele retirou para ler, corrigindo a tarefa que ele fez, valorizando, assim, as suas realizações, esse aluno terá satisfação de executar o que o professor solicitar.

Um dos sujeitos disse que seu aluno demonstrou sentir-se igual aos outros quando soube que poucos colegas obtiveram média alta no final do bimestre. Parece-nos que esse é um fato que normalmente acontece com o aluno que apresenta dificuldade de aprendizagem. Embora ele tenha consciência de sua dificuldade e isso, de fato, o incomode demais, ele não quer parecer menos capaz que os outros, apresentando resultados insatisfatórios. Segundo Tápia (2000), para o aluno, o reconhecimento dos colegas, a imagem que o outro tem dele é muito importante.

Outro sujeito disse que as crianças reagem bem à sua intervenção, passando a mostrar entusiasmo pelas atividades que fazem. Essa reação positiva parece mostrar que o aluno aumentou seu nível de aspiração, motivação e engajamento para com as suas tarefas. São crianças que, em virtude da ação do professor, passaram a exercer auto-controle sobre suas ações. Segundo Boruchovitch (1994), cabe, portanto, ao professor mostrar para seu aluno qual é exatamente o tipo de esforço que ele deve fazer para melhorar ainda mais.
Para a autora, quanto mais o aluno percebe-se melhor, melhores são as construções cognitivas nas suas ações. As metas estabelecidas por ele dependem do quanto se sente eficiente para realizá-las. Assim, quando o aluno vivencia atividades praze-rosas e desafiadoras, que lhe dão vontade de aprender, o fascinam e o envolvem, sem dúvida sua reação é positiva frente à intervenção do professor. Ao contrário, conforme verificou Marcellino (1988) em seus estudos, quando dentro da sala de aula se estabelece um clima de ameaça e punição para os desinteressados pelas atividades, as respostas são desde as mais conformistas até as mais indisciplinadas.

Podemos, também, associar o êxito da criança na escola com as regras estabelecidas pelo professor na sala de aula. Muitas vezes, essas regras não são totalmente conhecidas pelos alunos e eles têm que ir descobrindoas e dominando-as ao longo do processo. Os alunos que reagem bem a essas regras são os que terão êxito em seu desempenho, conforme estudos apresentados por Bueno e Garcia (1996). Segundo esses autores, são regras não explícitas que os alunos acabam por identificar gradualmente, por meio da interação social que estabelecem no contexto escolar.

A reação do aluno depende, muitas vezes, dos fatores que ele considera causadores de sua dificuldade. Se ele atribui o seu fracasso à falta de inteligência, por exemplo, será mais 
difícil para ele acreditar em sua capacidade de realizações.

Segundo Boruchovitch (1994), o aluno tende a se considerar com baixa capacidade quando o professor the faz elogios mesmo quando fracassa, ou quando não o repreende se ele não tem bom desempenho numa tarefa tida de nível baixo. Portanto, para a autora, a reação da criança é tanto melhor quanto mais ela consegue relacionar o seu esforço com o grau de sucesso alcançado.

Chamou-nos a atenção o fato de um sujeito afirmar que, já que cada criança tem seu tempo para aprender, seus alunos com dificuldade de aprendizagem "estão aprendendo no seu tempo" e que ele respeita isso. Sua afirmação está relacionada ao conceito piagetiano, que considera as etapas de desenvolvimento das estruturas cognitivas.

Na verdade, essa ocorrência é comum ocorrer no início da alfabetização de alguns alunos. Aquele que parecia patinar na aprendizagem, que não conseguia assimilar os conteúdos, nem se interessava em realizar suas tarefas no momento em que seus colegas estavam aprendendo, depois de algum tempo, de repente, começa a demonstrar uma certa motivação. Faz as primeiras tentativas, depara-se com obstáculos, mostra disposição para enfrentá-los e logo passa a realizar suas atividades de maneira satisfatória.

Para alguns professores, esse "clic"ou "estalo", como muitos o de- nominam, essa transformação do aluno simplesmente aconteceu e eles não sabem dizer como aconteceu e nem por que aconteceu. Às vezes, atribuem o fato ao acaso, à sorte, às ameaças que fizeram e ao próprio método que utilizaram, sem se darem conta de que a criança apenas seguiu o ritmo de amadurecimento de suas estruturas mentais. A partir daí, a criança que já possuía uma lógica interna capaz de assimilar os conteúdos - estava pronta para o início do processo de aprendizagem de dado conteúdo.

A esse respeito, Ferreiro e Teberosky (1985) afirmam em suas pesquisas que a apropriação do conhecimento pela criança tem uma estrutura lógica a seguir e que o processo de aprendizagem só se efetivará quando elas avançarem em seu desenvolvimento conceitual.

Quando os professores disseram que os alunos com dificuldade de aprendizagem aceitam a ajuda dos colegas e muitas vezes os procuram para sanar suas dúvidas, na verdade pode estar ocorrendo aprendizagem no processo de interação social, que, segundo Coll Salvador (1994), acontece quando a criança aprende a regular seus processos cognitivos, através da orientação dos adultos ou de um colega que sabe mais do que ela. Para o autor, mediante a ajuda do colega, o aluno interioriza o que está aprendendo e o transforma, progressivamente, em algo que ele pode conhecer por si mesmo.

Essa aprendizagem com a ajuda do 
colega corresponde, também, ao que a teoria vygotskyana chama de zona de desenvolvimento proximal, pois a intervenção do colega levou o aluno a ir além do que aprenderia sozinho; levou-o a desenvolver o seu potencial de aprendizagem.

\section{CONSIDERAÇÕES FINAIS}

Neste estudo buscamos analisar, através da análise das respostas dos professores, obtidas em entrevista semi-estruturada, o que eles dizem fazer para ajudar os alunos que apresentam dificuldades de aprendizagem e como essas crianças reagem diante de suas intervenções.

Os resultados obtidos revelam que a intervenção dos professores para ajudar seus alunos no enfrentamento das dificuldades que apresentam, ocorre de forma pedagógica e afetiva. De acordo com a fala dos professores, pedagogicamente, suas ações estão direcionadas às particularidades pontuais de dificuldade dos alunos, que compreendem algumas atividades diferenciadas na sala de aula e na tarefa de casa e, de forma unânime, no encaminhamento desses alunos ao reforço escolar.

No aspecto afetivo, os professores têm se voltado à motivação e ao incentivo dos alunos, conversando, questionando, elogiando ou advertindo de maneira encorajadora, atentos às diferenças de nível de desenvolvimento e de temperamento e à adequação do momento, para não atingir ne- gativamente a auto-estima da criança. Consideramos positiva a afirmação dos professores de que o fato de salientarem apenas os desacertos do aluno frente à aprendizagem, em nada o auxilia para melhorar seu desempenho. Pelo contrário, só o empurra a convencer-se da sua incapacidade e entregar-se ao círculo vicioso do fracasso.

Segundo as respostas analisadas, ao perceber-se "cuidada"ou apoiada pelo seu professor, a criança reage de forma positiva, demonstrando mais entusiasmo e disposição na execução das atividades. Ela quer mostrar ao professor que as executou, para receber mais elogio: pode ser criado, então, o círculo virtuoso da aprendizagem e do sucesso escolar. Também, as crianças apresentam-se mais carinhosas, querendo presentear o professor com seus "feitos" (desenhos, cartinhas etc) ou com sua aproximação física (beijos, abraços etc).

Na opinião dos professores, a criança percebe a preocupação e a dedicação do professor e, com isso, sente-se amparada ao enfrentar uma dificuldade, pois sabe que pode contar com a sua compreensão e atenção.

De forma geral, os professores demonstram tranqüilidade e segurança ao relatar suas intervenções, manifestando o sentimento de que fazem o melhor para os alunos. Mas, qual é o professor que se encontra, realmente, em condições favoráveis de observar seus alunos, avaliar as capacidades deles, reconhecer as dificulda- 
des que têm e intervir eficazmente, buscando e encontrando metodologias adequadas às particularidades de cada um? Qual é o professor que questionará suas ações e refletirá sobre elas, de maneira crítica?

Sabemos que, se formos responder a essas questões, teremos que considerar que somente o professor "bem" formado profissional e pessoalmente atuará positivamente no enfrentamento das dificuldades de aprendizagem dos alunos. E que o conhecimento que utiliza na sala de aula, em sua atuação, ele adquiriu não só em sua formação docente, mas é fruto, também, da cultura de escola que ele tem, da idéia de escola que ele traz de suas vivências como aluno e de experiências pedagógicas que lhe mostram como o professor deve proceder. Portanto, a forma de intervenção do professor será mais, ou menos eficiente, dependendo de como ele aprendeu a ensinar e de como ele pensa que deve ensinar.

\section{REFERÊNCIAS}

BORUCHOVITCH, E. As variáveis psicológicas e o processo de aprendizagem: uma contribuição para a psicologia escolar. Psicologia - Teoria e Pesquisa, Brasília, v. 10, n. 1, p. 129-139, 1994.

BRASIL. Ministério da Educação. Proposta de diretrizes para a formação inicial de professores da educação básica em cursos de nível superior. Brasília: MEC, mai. 2000.
BUENO, B. O.; GARCIA, T. F. Êxito escolar: as regras da interação na sala de aula. Revista Brasileira de Estudos Pedagógicos, Brasília. v. 77, n. 186, p. 263281, mai.-ago. 1996.

CAMPOS, L. M. L. A rotulação de alunos como portadores de "distúrbios ou dificuldades de aprendizagem": uma questão a ser refletida. Série Idéias, São Paulo, n. 28, p. 125-139, 1997.

CANDAU, V. M. Formação continuada de professores: tendências atuais. In: REALLI, A. M. M. R.; MIZUKAMI, M. G. (Orgs.). Formação de professores: tendências atuais. São Carlos: EDUFSCar, 1996.

CARVALHO, J. S. F. Os sentidos da (in)disciplina: regras e métodos como práticas sociais. In: AQUINO, J. G. (Org.). Indisciplina na escola: alternativas teóricas e práticas. São Paulo: Summus, 1996.

CAVACO, M. H. O ofício do professor: o tempo e a mudança. In: NÓVOA, A. Profissão professor. Porto, Pt: Porto Editorial, 1991.

CHAKUR, C. R. S. L.; RAVAGNANI, M. C. R. N. Inteligência e fracasso escolar: problema prático para a educação, questão teórica para a psicologia. In: CHAKUR, C. R. S. L. (Org.). Problemas da educação sob o olhar da psicologia. Araraquara: UNESP; São Paulo: CAE, 2001.

COLL SAlVADOR, C. C. Aprendizagem escolar e construção do conhecimento. Porto Alegre: Artes Médicas, 1994.

CRUZ, S. A. B. A avaliação da aprendizagem na política educacional da Secretaria da Educação do Estado de São Paulo. Monografia (Especialização em 
Psicopedagogia) - Centro Universitário de Araraquara, Araraquara, 2000.

DAVIS, C.; ESPOSITO, Y. L. O papel e a função do erro na avaliação escolar. Revista Brasileira de Estudos Pedagógicos, Brasília, v. 72, n. 171, p. 196-206, mai.-ago. 1991.

DEL PRETTE, Z. A.; DEL PRETTE, A. Desenvolvimento interpessoal e educação escolar: o enfoque das habilidades sociais. Temas em Psicologia, Ribeirão Preto: SBP, v. 6, n. 3, p. 205-215, 1998.

FERREIRO, E.; TEBEROSKY, A. Psicogênese da língua escrita. Porto Alegre: Artes Médicas, 1985.

GARCÍA, J. N. Manual de dificuldades de aprendizagem: linguagem, leitura, escrita e matemática. Porto Alegre: Artes Médicas, 1998.

JACOB, A.V.; LOUREIRO, S. R. Desenvolvimento afetivo: o processo de aprendizagem e o atraso escolar. Paidéia, Ribeirão Preto: FFCLRP-USP, fev.-ago. 1996.

LINHARES, M. B. M. Avaliação assistida de crianças com queixa de dificuldade de aprendizagem: indicadores de eficiência e transferência de aprendizagem em situação de resolução de problema. In: ZUARDI, A. W. et al. (Orgs.). Estudos em saúde mental. Ribeirão Preto: FMRP/USP, 1998.

LÜDKE, M.; ANDRÉ, M. E. D. A. Pesquisa em educação: abordagens qualitativas. São Paulo: EPU, 1986.

MACHADO, V. L. S. et al. Crianças com dificuldades na aprendizagem escolar: características de comportamento conforme avaliação de pais e professores. Arquivos brasileiros de Psicologia, v. 46, n. 3/4, p. 119-138, 1994.
MARCELLINO, N. C. A sala de aula como espaço para o "jogo do saber". In: MORAES, R. (Org.). Sala de aula: que espaço é esse? Campinas: Papirus, 1988.

MARCELO, C. Pesquisa sobre a formação de professores: o conhecimento sobre aprender a ensinar. Revista Brasileira de Educação, São Paulo: ANPEd, n. 4, set.dez. 1998.

MARIN, A. J. Propondo um novo paradigma para formar professores a partir das dificuldades e necessidades históricas nessa área. In: REALLI, A. M. R.; MIZUKAMI, M. G. (Orgs.). Formação de professores: tendências atuais. São Carlos: EDUFSCar, 1996.

MINAYO, M. C. S. O desafio do conhecimento: pesquisa qualitativa em saúde. Rio de Janeiro: Abrasco, 2000.

PELEGRINI, R. M.; GOLFETO, J. H. Problemas de aprendizagem: um enfoque em Psiquiatria infantil. In: FUNAYAMA, C. A. (Org.). Problemas de aprendizagem: enfoque multidisciplinar. Ribeirão Preto: Legis Summa, 1998.

PÉREZ GÓMEZ, A. O pensamento prático do professor: a formação do professor como profissional reflexivo. In: NOVOA, A. (Coord.). Os professores e sua formação. Lisboa: Dom Quixote, 1992.

PIAGET, J. Seis estudos de psicologia. Rio de Janeiro: Forense Universitária, 1998.

PIAGET, J.; GRÉCCO, P. Aprendizagem e conhecimento. Rio de Janeiro: Livraria Freitas Bastos, 1974.

SCHLIEMANN, A. D.; CARRAHER, D. W.; CARRAHER, T. N. Na vida dez, na escola zero. São Paulo: Cortez, 1995.

SELLTIZ, C. et al. Métodos de pesquisa das relações sociais. São Paulo: Herder, 1965. 
TÁPIA, J. A. Contexto, motivação e aprendizagem. In: TÁPIA, J. A.; FITA, E. C. A motivação em sala de aula: o que é, como se faz. São Paulo: Loyola, 2000.

TRIVIÑOS, A. N. S. Introdução à pesquisa em ciências sociais: a pesquisa qualitativa em educação. São Paulo: Atlas, 1987.

VILLA SANCHES, A. La formación del professorado em la encrucijada. In: VILLA SANCHES, A. Perspectivas y problemas de la función docente. Madrid: Narcea, 1988.

VYGOTSKY, L. S. A. A formação social da mente: o desenvolvimento dos processos psicológicos superiores. São Paulo: Martins Fontes, 1991.

WEISS, M. L. L. Psicopedagogia clínica: uma visão diagnóstica dos problemas de aprendizagem escolar. Rio de Janeiro: DP\&A, 1997.

Encaminhado em 18/03/05

Aceito em 06/07/05 